\title{
Projeto: A Casa
}

Thaíse Martins Ricardo

Email: tatai_vip@hotmail.com

\section{A Casa}

Era uma casa muito engraçada Não tinha teto, não tinha nada Ninguém podia entrar nela, não Porque na casa não tinha chão Ninguém podia dormir na rede

\begin{abstract}
Porque na casa não tinha parede
Ninguém podia fazer pipi

Porque penico não tinha ali

Mas era feita com muito esmero

na rua dos bobos numero zero.
\end{abstract}

(Vinicius de Moraes )

No inicio do ano letivo de 2011, era uma casinha assim na qual as crianças da pré-escola imaginavam estar na prazerosa brincadeira.

Auxiliados por sua imaginação as crianças idealizavam cada canto da casinha: sala, cozinha, quartos, banheiro, enfim, nenhum cantinho escapava!
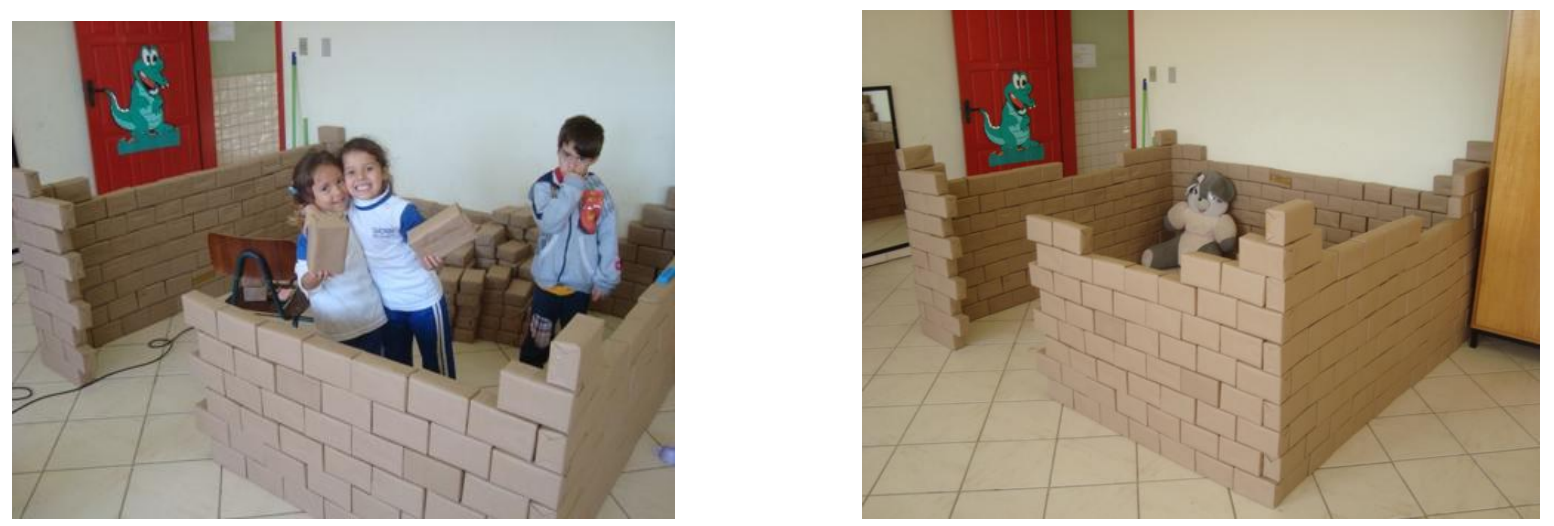

Foi observando o grande interesse das crianças pela brincadeira de "casinha", que resolvemos construir, dentro do espaço da sala de aula, uma casa na qual as crianças pudessem organizar as mais diversas brincadeiras de faz de conta, especialmente a de "casinha".

Antes da construção ter inicio, pensamos também em utilizar materiais que poderiam ser reaproveitados, contribuindo também para a reutilização destes materiais e para a preservação do meio ambiente, dando um novo destino ao que chamávamos de lixo.

Decidimos então que o material mais adequado para a construção da "obra" seriam as caixas de leite, que se assemelham aos tijolos de uma construção convencional.

Decidido isso, teve inicio um grande período de arrecadação de caixas de leite vazias, onde todas as crianças e alguns outros personagens da comunidade escolar participaram intensamente, trazendo as caixas diariamente até a escola. 
Arrecadamos aproximadamente 700 caixas de leite para a estrutura das paredes e do telhado, para este último, foram utilizadas caixas de leite abertas.
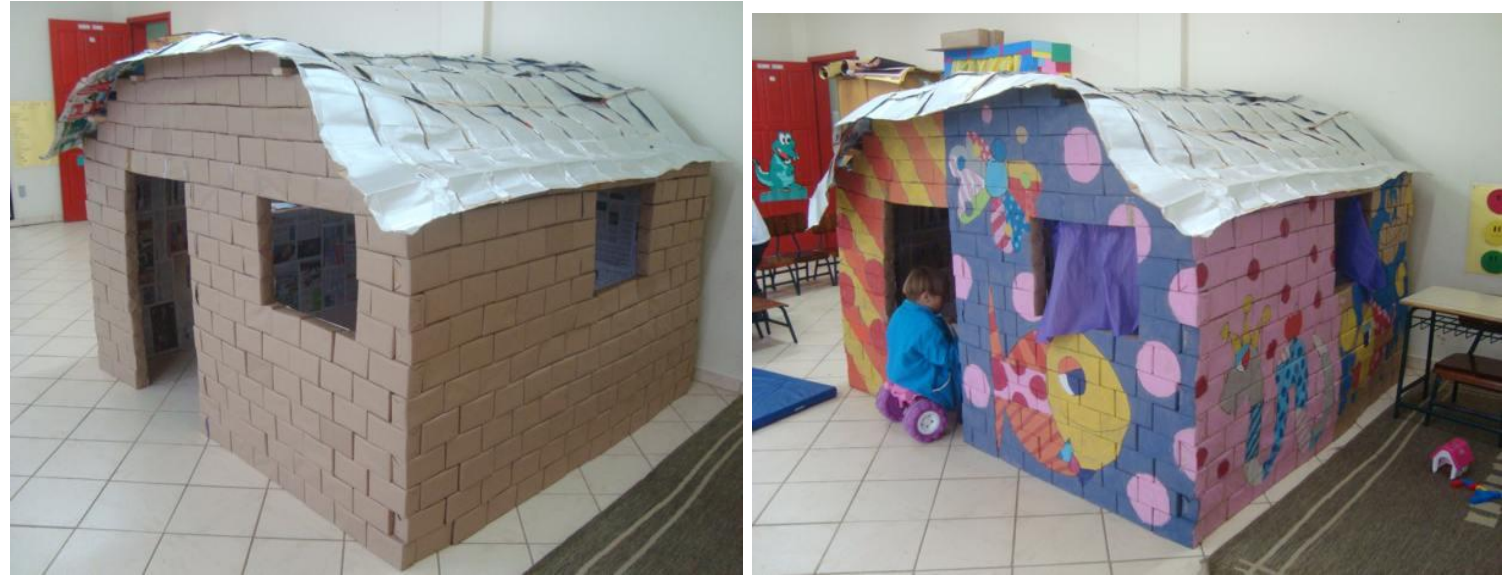

Com o sucesso da arrecadação, dois meses depois, as crianças puderam imaginar como seria esta casinha, quantas portas e janelas ela teria, quão alta ela poderia ser, quanto tempo se levaria para finalizar esta obra, foi então que decidimos como seria a estrutura da casa: Uma porta e três janelas.
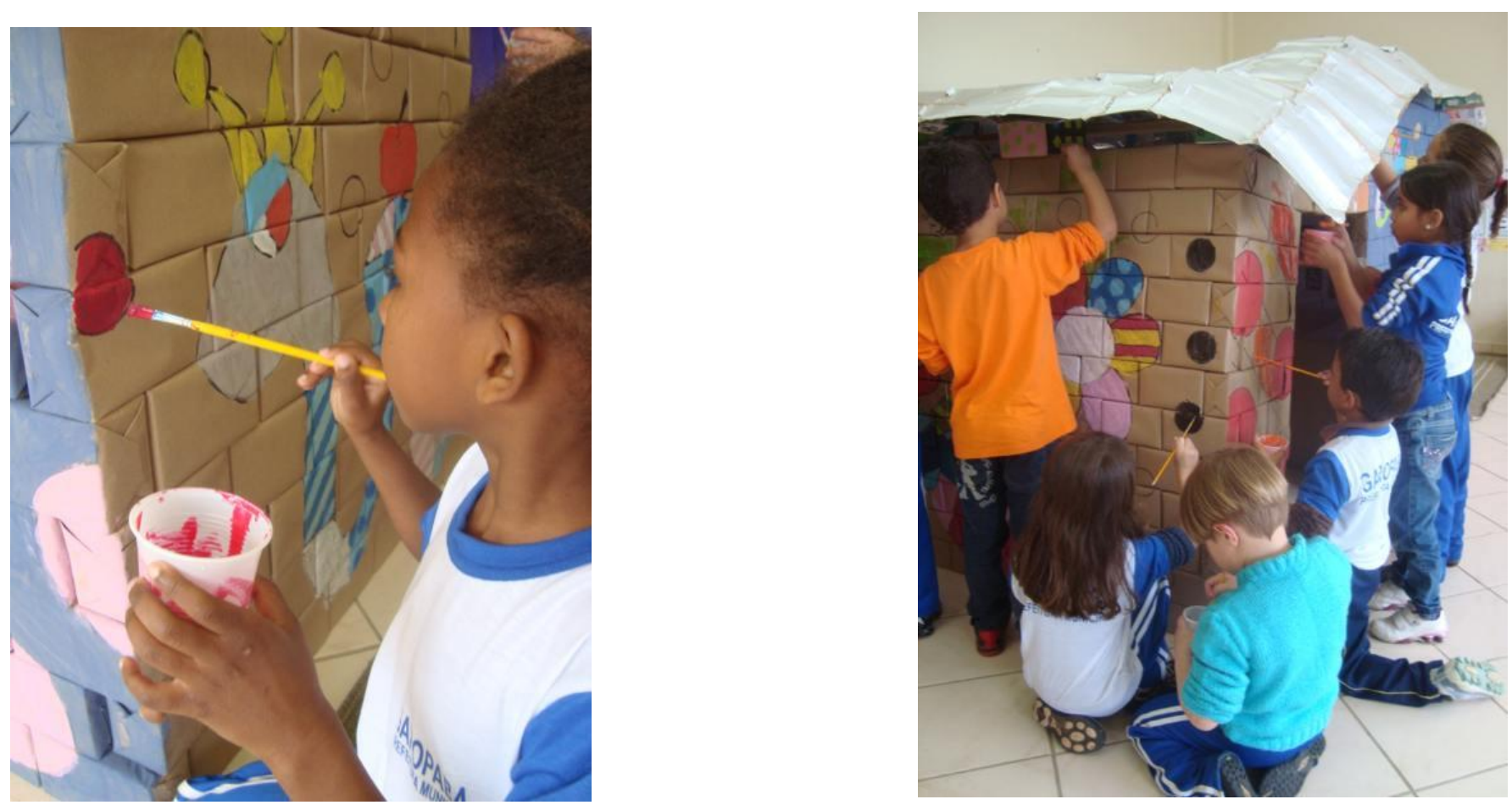

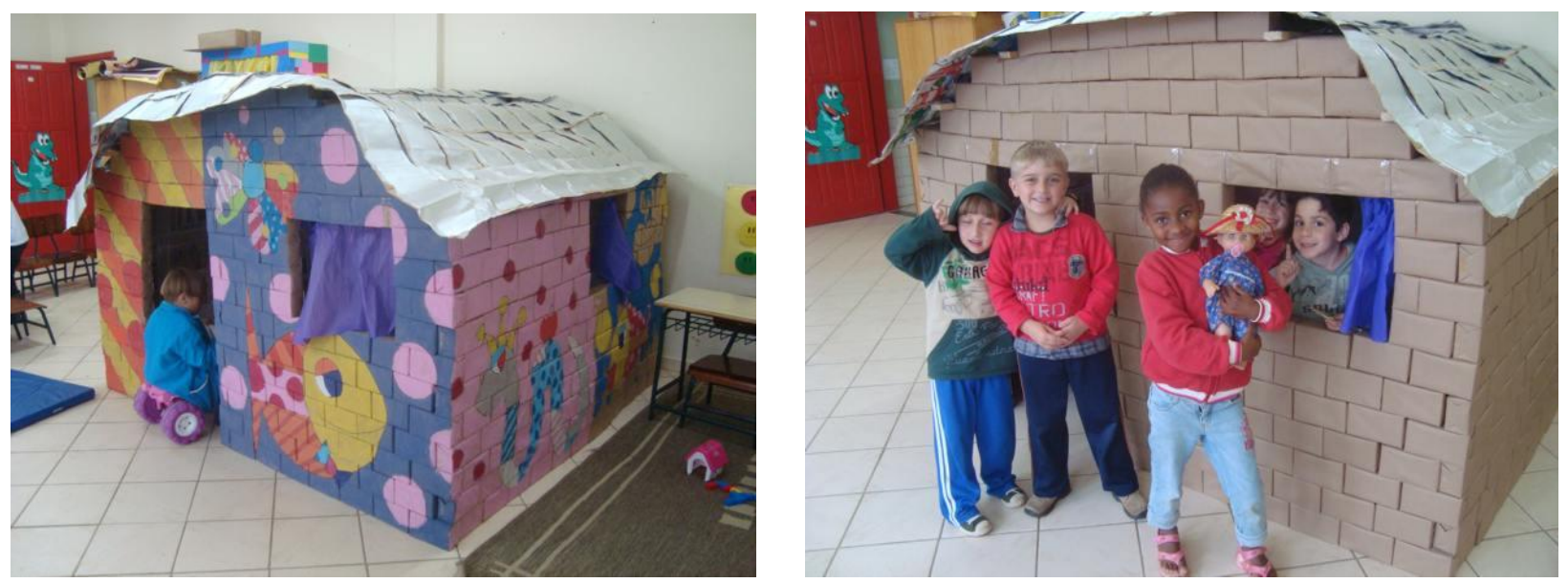

A partir daí, teve início um intenso trabalho para que esta "obra" fosse finalizada o mais rápido possível, e é claro, que os 'pequeninos fiscais' estavam ali bem pertinho, observando e participando de todas as etapas dessa 'grande construção.'

Passado mais um mês, finalmente a "obra" estava chegando ao final e as crianças, ansiosas para explorar o novo ambiente, ainda que já brincassem ali antes mesmo de terem a casinha pronta.

Não podíamos parar por ali! Casa que é casa merece um teto, certo?! Então, mãos à obra!

Abrir cem caixas de leite não foi tarefa fácil, mas o resultado foi confortador: um telhado prateado cobrindo o segundo novo "lar" dos pequeninos, a casinha estava pronta!

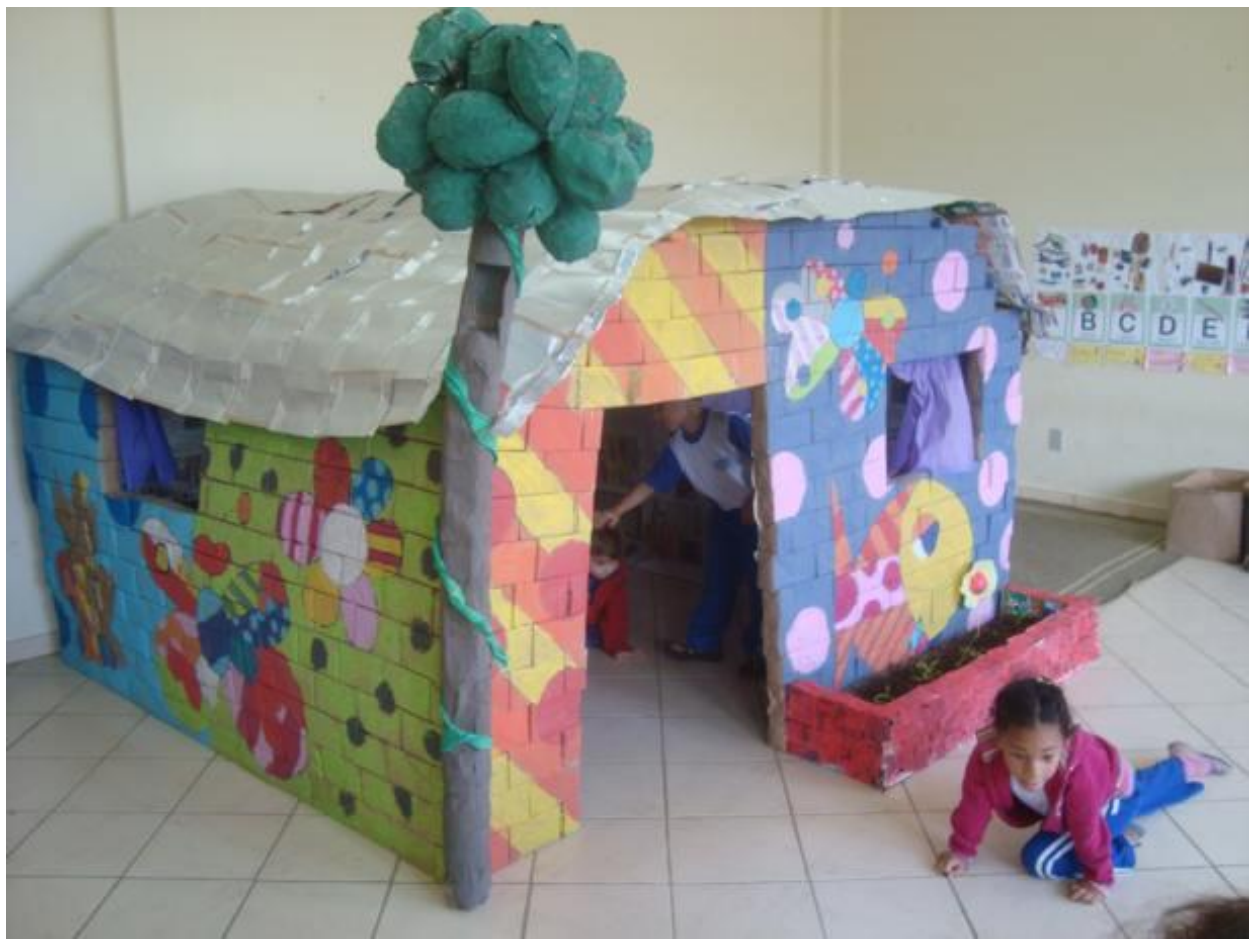


Mas não paramos por aí, para embelezar ainda mais este ambiente, tornando-o ainda mais estimulante para as crianças, decidimos construir um pequeno jardim de girassóis em baixo de uma das janelinhas, em seguida, montamos uma árvore com garrafas PET ( lugar onde vive um pequeno pássaro trazido por uma das crianças).
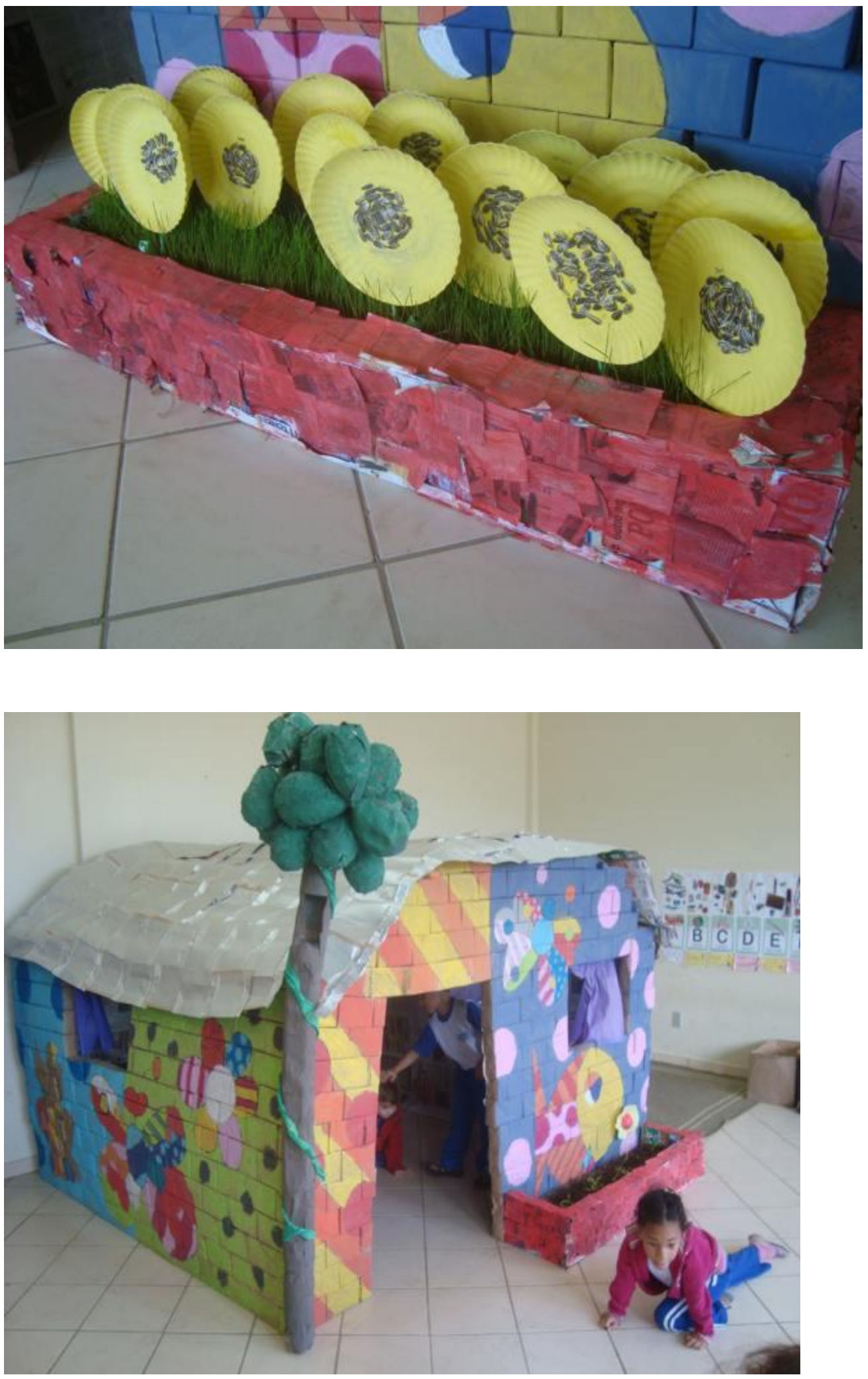
O espaço da casinha é um ambiente que tem proporcionado as crianças da pré escola, momentos de prazer, de alegria, de novas descobertas e vivências; pois ali eles podem experimentar e explorar uma das brincadeiras mais escolhidas por "crianças de ontem, de hoje e de sempre".

E você?

Já brincou de casinha hoje?

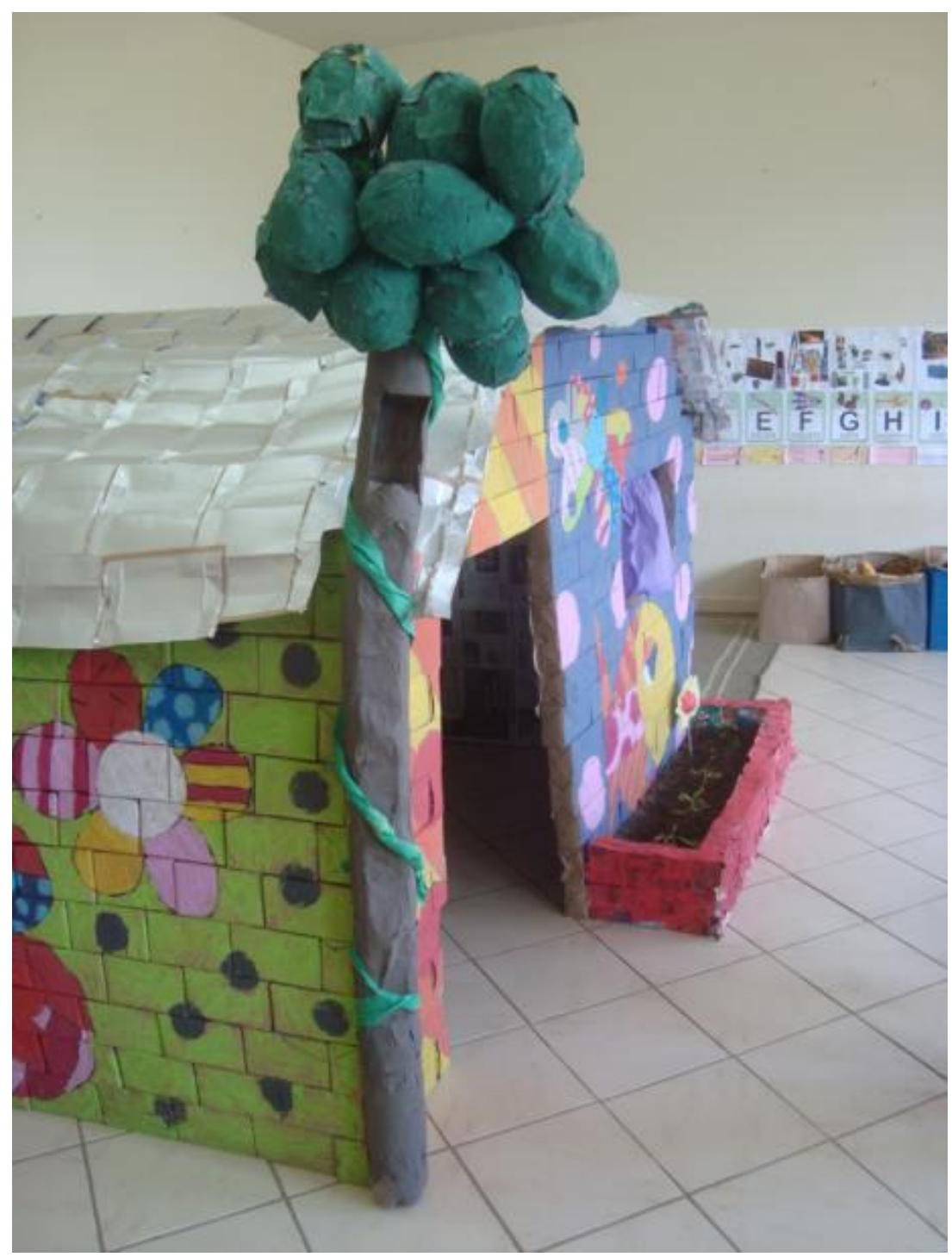

E.E. Básica Maria Corrêa Saad

Turma: Pré Escolar 01, 02 (4 a 6 anos)

Professora Thaíse Martins Ricardo

Graduada em Pedagogia da

Educação Infantil e dos Anos Iniciais (UNIASSELVI)

Pós graduada em Práticas

Interdisciplinares (FUCAP) 